\title{
Asymmetric bioreduction of $\beta$-ketoesters derivatives by Kluyveromyces marxianus: influence of molecular structure on the conversion and enantiomeric excess
}

\author{
SIMONE S.S. OLIVEIRA ${ }^{1}$, MURILO L. BELLO ${ }^{2}$, CARLOS R. RODRIGUES ${ }^{2}$, PAULA L. DE AZEVEDO ${ }^{3}$, \\ MARIA C.K.V. RAMOS $^{3}$, FRANCISCO R. DE AQUINO-NETO ${ }^{3}$, SORELE B. FIAUX ${ }^{1}$ and LUIZA R.S. DIAS ${ }^{1}$ \\ ${ }^{1}$ Faculdade de Farmácia, Universidade Federal Fluminense/UFF, Rua Mário \\ Viana, 523, Santa Rosa, 24241-000 Niterói, RJ, Brazil \\ ${ }^{2}$ Faculdade de Farmácia, Universidade Federal do Rio de Janeiro/UFRJ, Centro de Ciências da Saúde, \\ Av. Carlos Chagas Filho, 373, Cidade Universitária, 21941-599 Rio de Janeiro, RJ, Brazil \\ ${ }^{3}$ Instituto de Química, Universidade Federal do Rio de Janeiro/UFRJ, Centro de Tecnologia, Av. Athos \\ da Silveira Ramos, 149, Bloco A, Cidade Universitária, 21941-909 Rio de Janeiro, RJ, Brazil
}

Manuscript received on February 15, 2017; accepted for publication on March 28, 2017

\begin{abstract}
This study presents the bioreduction of six $\beta$-ketoesters by whole cells of Kluyveromyces marxianus and molecular investigation of a series of $13 \beta$-ketoesters by hologram quantitative structure-activity relationship (HQSAR) in order to relate with conversion and enantiomeric excess of $\beta$-stereogenichydroxyesters obtained by the same methodology. Four of these were obtained as $(R)$-configuration and two $(S)$-configuration, among them four compounds exhibited $>99 \%$ enantiomeric excess. The $\beta$-ketoesters series LUMO maps showed that the $\beta$-carbon of the ketoester scaffold are exposed to undergo nucleophilic attack, suggesting a more favorable $\beta$-carbon side to enzymatic reduction based on adopted molecular conformation at the reaction moment. The HQSAR method was performed on the $\beta$-ketoesters derivatives separating them into those provided predominantly $(R)$ - or $(S)$ - $\beta$-hydroxyesters. The HQSAR models for both $(R)$ - and $(S)$-configuration showed high predictive capacity. The HQSAR contribution maps suggest the importance of $\beta$-ketoesters scaffold as well as the substituents attached therein to asymmetric reduction, showing a possible influence of the ester group carbonyl position on the molecular conformation in the enzyme catalytic site, exposing a $\beta$-carbon side to the bioconversion to $(S)$ - and $(R)$-enantiomers.
\end{abstract}

Key words: biocatalysis, $\beta$-ketoesters, $\beta$-hydroxyesters, HQSAR, whole cell bioreduction.

\section{INTRODUCTION}

Chiral $\beta$-hydroxyesters are widely used in the chemical-pharmaceutical industry as intermediates of organic synthesis and some of them have been used for the synthesis of

Correspondence to: Luiza Rosaria Sousa Dias

E-mail: 1rsdias@id.uff.br biologically active compounds. For example, the ethyl 3-hydroxybutanoate plays an important role in the synthesis of $(+)$-decarestrictine $L$, an inhibitor of cholesterol biosynthesis (Wang et al. 2013), and the methyl 3-hydroxypentanoate is the key chiral building block in the synthesis of (-)-serricornine, the sex pheromone from cigarette 
beetle, Lasioderma serricorne (Pilli and Riatto 1998). In the same way, ethyl 3-hydroxyhexanoate is an important intermediate for the synthesis of $(+)$-neopeltolide, a potent in vitro antiproliferative agent against the growth of several cancer cell lines and also antifungal activity against Candida albicans (Ramos et al. 2011, Ghosh et al. 2013). And also both enantiomeric forms of methyl 3-aryl-3-hydroxypropionates are important building blocks in the synthesis of several chiral drugs, fine chemicals and pesticides (Borowiecki and Bretner 2013, Liu and Liu 2015).

Chiral $\beta$-hydroxyesters from $\beta$-ketoesters may be obtained by chemical or microbial asymmetric reduction. The chemical asymmetric methods involve metal catalysts that may leave residues in products and should be avoided for pharmaceuticals. Aside from that it generally requires additional steps for protection/deprotection of functional groups and extreme reaction conditions (Hagemann et al. 2005, Ng and Jaenicke 2009, Floris et al. 2009, Sheldon 2016). Alternatively the bioreduction occurs under nontoxic and mild reaction conditions (ambient temperature, atmospheric pressure, and aqueous medium) with little impact on the environmental and avoids the burden of groupprotecting procedures (Milner and Maguire 2012, Oliveira et al. 2013, Regil and Sandoval 2013, Sheldon 2016).

Despite the bioreduction approaches require special precautions, such as sterile conditions to obtain the biomass and a biphasic system or substrate/product reservoir in order to get around the low water solubility of the substrates, this method is attractive because of its advantages and has been widely used for asymmetric reductions (Zeror et al. 2010, Regil and Sandoval 2013, Sheldon 2016, Wachtmeister and Rother 2016).

Asymmetric bioreductions can be performed using both enzymes and whole cells. The use of whole cells has the additional advantage of containing the required cofactors and regenerates them during the reaction (Milner and Maguire 2012, Nakamura et al. 2003, Illanes et al. 2012, Venkataraman and Chadha 2015, Wei et al. 2016).

Several microorganisms have been used to reduce different $\beta$-ketoesters and most of them catalyze the reaction to the $(S)$-configuration (Ramos et al. 2009a). Saccharomyces cerevisiae (baker's yeast) is the most used microorganism to obtain some chiral $\beta$-hydroxyesters (Zeror et al. 2010, Fow et al. 2008) due to its ease of handling and commercial availability. However, this method gives predominantly $(S)$-configuration products, with wide range of enantiomeric excess (Zeror et al. 2010, Dahl and Madsen 1998, Mahmoodi et al. 2006).

The yeast Kluyveromyces marxianus has several characteristics that make it an excellent choice for commercial processes. These includes low $\mathrm{pH}$ tolerance, high resistance to furfural and alcohols, a broad range of fermentation temperatures (thermotolerance), and the ability to grow fast and on a wide variety of inexpensive carbon source (Moreno et al. 2012, Chang et al. 2014, Galindo-Leva et al. 2016). Some biotechnological applications have been reported using this yeast, such as food, beverages, enzymes, and fine chemicals production (Foukis et al. 2012, Lane et al. 2011).

In the present work six $\beta$-ketoesters (compounds 1-6) were submitted to asymmetric bioreduction by whole cells of $K$. marxianus. The bioconversion result of these compounds were added to seven others $\beta$-ketoesters (compounds 7-13) from the literature to study the structural influence of $\beta$-ketoesters substrate on the activity of this yeast (Table I). In an attempt to understand which structural properties are crucial for the enantiomers biosynthesis, the two-dimensional molecular features of the $\beta$-ketoesters series were explored using the hologram quantitative structureactivity relationship (HQSAR) (Rodrigues et al. 2002, Magalhães et al. 2013). 


\section{MATERIALS AND METHODS}

\section{CHEMICALS}

The following $\beta$-ketoesters were used as substrates: ethyl 3-oxobutanoate (1), methyl 3-oxopentanoate (2), ethyl3-oxopentanoate(3), ethyl3-oxohexanoate (4), methyl 4-chloro-3-oxobutanoate (5), methyl 3-(4-chlorophenyl)-3-oxopropanoate (6). All chemicals were obtained from Sigma-Aldrich.

\section{MICROORGANISM AND GROWTH CONDITIONS}

The yeast Kluyveromyces marxianus belongs to the collection of the Departamento de Engenharia Bioquímica of the Escola de Química at the Universidade Federal do Rio de Janeiro, Brazil.

Cells of $K$. marxianus were allowed to grow at $30{ }^{\circ} \mathrm{C}$ under $150 \mathrm{rpm}$ for $48 \mathrm{~h}$ in Erlenmeyer flask $(250 \mathrm{~mL})$ with $50 \mathrm{~mL}$ of sterile growth medium containing $10 \mathrm{~g} / \mathrm{L}$ glucose, $5 \mathrm{~g} / \mathrm{L}$ yeast extract, 5 $\mathrm{g} / \mathrm{L}$ peptone, $1 \mathrm{~g} / \mathrm{L}\left(\mathrm{NH}_{4}\right)_{2} \mathrm{SO}_{4}, 1 \mathrm{~g} / \mathrm{L} \mathrm{MgSO}_{4} \cdot 7 \mathrm{H}_{2} \mathrm{O}$ and $\mathrm{pH}$ 6.5. The grown cells were harvested by centrifugation at $3500 \mathrm{rpm}$ for $10 \mathrm{~min}$. The cells were washed twice with distilled water and used in the bioconversion.

\section{BIOCONVERSION CONDITIONS AND ANALYSIS OF THE PRODUCTS}

The bioconversion was carried out in a $250 \mathrm{~mL}$ Erlenmeyer flask with $50 \mathrm{~mL}$ medium containing 50 $\mathrm{g} / \mathrm{L}$ glucose and $1 \mathrm{~g} / \mathrm{L} \mathrm{MgCl}_{2}$ and $\mathrm{pH} 6.5$ (Ramos et al. 2009a). The $K$. marxianus cells were inoculated to the bioconversion's medium ( $5 \mathrm{~g} / \mathrm{L}$, dry weight). After $30 \mathrm{~min}$ of inoculation under agitation (150 rpm) at $30{ }^{\circ} \mathrm{C}$, each Erlenmeyer flask received appropriate $\beta$-ketoester $(0.5 \%)$ in aqueous-ethanol. After $24 \mathrm{~h}$ of incubation at the same conditions, the cells were harvested by centrifugation and the supernatant was extracted with ethyl acetate. The organic phase was dried (anhydrous $\mathrm{MgSO}_{4}$ ), filtered and concentrated under vacuum. The experiments were performed in triplicate.
The products were identified from infrared spectra (IR), optical rotations, and gas chromatography (GC). The IR spectra were recorded on a Perkin-Elmer 1420 spectrometer in potassium bromide pellets. Optical rotations were measured with a ACATEC PDA 9300 polarimeter at the sodium D line $(589 \mathrm{~nm})$ operating at $27^{\circ} \mathrm{C}$ using $\mathrm{CHCl}_{3}$ as solvent. The chromatographic analyses were performed with an HP 5890 instrument equipped with a flame ionization detector, $\mathrm{H}_{2}$ was used as the carrier gas, retention times $\left(t_{\mathrm{R}}\right)$ are given in minutes under each condition.

ETHYL 3-HYDROXYBUTANOATE (1'A AND 1'B)

Colorless oil; conversion 99\%; ee 81\%; IR ( $\mathrm{KBr}$, $\left.\mathrm{cm}^{-1}\right)$ : $3455(\mathrm{C}-\mathrm{OH}), 1732(\mathrm{C}=\mathrm{O}) .[\alpha] \mathrm{D}^{27}-16.3(\mathrm{c}$ $\left.1.0 \mathrm{CHCl}_{3}\right)$, lit.: $\left\{+43.7(S)\left(\mathrm{c} 1.0 \mathrm{CHCl}_{3}\right)\right\}(\mathrm{Dahl}$ and Madsen 1998). GC on chiral column BGB$176(25 \mathrm{~m} \times 0.25 \mathrm{~mm} \times 0.25 \mu \mathrm{m})$; isotherm 90 ${ }^{\circ} \mathrm{C}$; hydrogen carrier gas flow was $3.82 \mathrm{~mL} \mathrm{~min}^{-1}$, the inlet and flame ionization detector temperature was set to $250{ }^{\circ} \mathrm{C}$; split ratio, 1:100; injection volume, $1 \mu \mathrm{L}$. The elution order was: ethyl $(S)$-3hydroxybutanoate $\left(\mathbf{1}^{\prime} \mathbf{a}\right), t_{\mathrm{R}}=3.9 \mathrm{~min}$, followed by ethyl $(R)$-3-hydroxybutanoate (1'b), $t_{\mathrm{R}}=4.0 \mathrm{~min}$. Substrate (1) was eluted at $3.6 \mathrm{~min}$.

METHYL 3-HYDROXYPENTANOATE (2'A AND 2'B)

Colorless oil; conversion 73\%; ee 99\%; IR ( $\mathrm{KBr}$, $\left.\mathrm{cm}^{-1}\right): 3426(\mathrm{C}-\mathrm{OH}), 1637(\mathrm{C}=\mathrm{O}) .[\alpha] \mathrm{D}^{27}-10.6(\mathrm{c}$ $\left.1.0 \mathrm{CHCl}_{3}\right)$, lit.: $\left\{-32.8\right.$ (c $\left.\left.1.0 \mathrm{CHCl}_{3}\right)\right\}(\mathrm{Dahl}$ and Madsen 1998). GC on chiral column BGB-176 (25 $\mathrm{m} \times 0.25 \mathrm{~mm} \times 0.25 \mu \mathrm{m}) ; 40{ }^{\circ} \mathrm{C} / / 5^{\circ} \mathrm{C} / \mathrm{min} / / 150{ }^{\circ} \mathrm{C}$; hydrogen carrier gas flow was $1.35 \mathrm{~mL} \mathrm{~min}^{-1}$, both inlet and flame-ionization detector temperatures were $250{ }^{\circ} \mathrm{C}$; split ratio, 1:20; injection volume, $1 \mu \mathrm{L}$. The elution order was: methyl $(S)$-3hydroxypentanoate (2'a), $t_{\mathrm{R}}=10.8 \mathrm{~min}$, followed by methyl $(R)$-3- hydroxypentanoate (2'b), $t_{\mathrm{R}}=$ $11.2 \mathrm{~min}$. Substrate (2) was eluted at $10.5 \mathrm{~min}$. 


\section{ETHYL 3-HYDROXYPENTANOATE (3'A AND 3'B)}

Colorless oil; conversion 85\%; ee 99\%; IR ( $\mathrm{KBr}$, $\left.\mathrm{cm}^{-1}\right): 3468(\mathrm{C}-\mathrm{OH}), 1717(\mathrm{C}=\mathrm{O}) .[\alpha] \mathrm{D}^{27}-13.6$ (c $1.0 \mathrm{CHCl}_{3}$ ), lit.: $\left\{+23.3(\mathrm{~S})\left(\right.\right.$ c $\left.\left.1.0 \mathrm{CHCl}_{3}\right)\right\}$ (Rodriguez et al. 2000). GC on chiral column BGB-176 (25 m x $0.25 \mathrm{~mm} \times 0.25 \mu \mathrm{m}) ; 40{ }^{\circ} \mathrm{C} / / 5$ ${ }^{\circ} \mathrm{C} / \mathrm{min} / / 150{ }^{\circ} \mathrm{C}$; hydrogen carrier gas flow was $1.35 \mathrm{~mL} \mathrm{~min}^{-1}$, both inlet and flame-ionization detector temperatures were $250{ }^{\circ} \mathrm{C}$; split ratio, 1:20; injection volume, $1 \mu \mathrm{L}$. The elution order was: ethyl $(S)$-3-hydroxypentanoate (3'a), $t_{\mathrm{R}}=12.5$ min, followed by ethyl $(R)$-3- hydroxypentanoate $\left(\mathbf{3}^{\prime} \mathbf{b}\right), t_{\mathrm{R}}=12.8 \mathrm{~min}$. Substrate (3) was eluted at $12.3 \mathrm{~min}$.

\section{ETHYL 3-HYDROXYHEXANOATE (4'A AND 4'B)}

Colorless oil; conversion 96\%; ee 99\%; IR ( $\mathrm{KBr}$, $\left.\mathrm{cm}^{-1}\right): 3518(\mathrm{C}-\mathrm{OH}), 1717(\mathrm{C}=\mathrm{O}) .[\alpha] \mathrm{D}^{27}-9.4(\mathrm{c}$ $\left.1.0 \mathrm{CHCl}_{3}\right)$, lit.: $\left\{-30.8\left(\right.\right.$ c $\left.\left.1.0 \mathrm{CHCl}_{3}\right)\right\}($ Ramos et al. 2011). GC on chiral column 10B (30 m x 0.25 $\mathrm{mm} \times 0.25 \mu \mathrm{m}) ; 90{ }^{\circ} \mathrm{C} / 20 \mathrm{~min}$; hydrogen carrier gas flow was $2.39 \mathrm{~mL} \mathrm{~min}^{-1}$; inlet at $250{ }^{\circ} \mathrm{C}$; flameionization detector at $270{ }^{\circ} \mathrm{C}$; split ratio, 1:20; injection volume, $1 \mu \mathrm{L}$. The elution order was: ethyl (S)-3-hydroxyhexanoate (4'a), $t_{\mathrm{R}}=16.2 \mathrm{~min}$, followed by ethyl $(R)$-3- hydroxyhexanoate (4'b), $t_{\mathrm{R}}=16.5 \mathrm{~min}$. Substrate (4) was eluted at $15.8 \mathrm{~min}$.

METHYL 4-CHLORO-3-HYDROXYBUTANOATE (5'A AND 5'B)

Colorless oil; conversion 13\%; ee 44\%; IR (KBr, $\left.\mathrm{cm}^{-1}\right): 3500(\mathrm{C}-\mathrm{OH}), 1731(\mathrm{C}=\mathrm{O}) .[\alpha] \mathrm{D}^{27}-6.4(\mathrm{c}$ $\left.1.0 \mathrm{CHCl}_{3}\right)$, lit.: $\left\{-8.0\left(\mathrm{c} 1.5 \mathrm{CHCl}_{3}\right)\right\}($ Seebach et al. 1984). GC on chiral column Lipodex E (25 m x $0.25 \mathrm{~mm}$ ); $70{ }^{\circ} \mathrm{C} / / 5{ }^{\circ} \mathrm{C} / \mathrm{min} / / 130{ }^{\circ} \mathrm{C}$; hydrogen carrier gas flow was $2.57 \mathrm{~mL} \mathrm{~min}^{-1}$, both inlet and flame-ionization detector temperatures were $250{ }^{\circ} \mathrm{C}$; split ratio, 1:100; injection volume, $1 \mu \mathrm{L}$. The elution order was: methyl $(R)$-4-chloro-3hydroxybutanoate $\left(\mathbf{5}^{\prime} \mathbf{b}\right), t_{\mathrm{R}}=10.7 \mathrm{~min}$, followed by methyl (S)-4-chloro-3-hydroxybutanoate (5'a), $t_{\mathrm{R}}=10.9 \mathrm{~min}$. Substrate (5) was eluted at $9.7 \mathrm{~min}$.

METHYL 3-(4-CHLOROPHENYL)-3HYDROXYPROPANOATE (6'A AND 6'B)

White solid; conversion 28\%; ee 99\%; IR ( $\mathrm{KBr}$, $\left.\mathrm{cm}^{-1}\right): 3521(\mathrm{C}-\mathrm{OH}), 1743(\mathrm{C}=\mathrm{O})$. [ $\left.\alpha\right]^{27}-8.7$ (c 1.0 EtOH), lit.: $\{-18.0$ (c 1.0 EtOH) $\}$ (RatovelomananaVidal et al. 2003). GC on chiral column 10B (30 $\mathrm{m} \times 0.25 \mathrm{~mm} \times 0.25 \mu \mathrm{m}) ; 150{ }^{\circ} \mathrm{C}(10 \mathrm{~min}) / / 1.5^{\circ} \mathrm{C} /$ $\mathrm{min} / / 190^{\circ} \mathrm{C}$; hydrogen carrier gas flow was 2.39 $\mathrm{mL} \min ^{-1}$; inlet at $250{ }^{\circ} \mathrm{C}$; flame-ionization detector at $270{ }^{\circ} \mathrm{C}$; split ratio, 1:20; injection volume, $1 \mu \mathrm{L}$. The elution order was: methyl 3-(4-chlorophenyl)$(R)$-3-hydroxypropanoate (6'b), $t_{\mathrm{R}}=23.4 \mathrm{~min}$, followed by methyl 3-(4-chlorophenyl)-(S)-3hydroxypropanoate (6'a), $t_{\mathrm{R}}=23.7 \mathrm{~min}$. Substrate (6) was eluted at $4.3 \mathrm{~min}$.

\section{$\mathrm{NABH}_{4}$ REDUCTION CONDITIONS}

The standards used in the analysis of the reactional products were obtained by chemical reduction of each one of the six $\beta$-ketoesters. The chemical reduction was conducted with sodium borohydride $\left(\mathrm{NaBH}_{4}\right)$ using glycerol as solvent at room temperature. After total consumption of the substrate the medium was acidified with $\mathrm{HCl}$ $10 \%(\mathrm{v} / \mathrm{v})$ and the product was extracted with ethyl acetate (Oliveira et al. 2014).

\section{MOLECULAR MODELING AND DETERMINATION} OF THREE-DIMENSIONAL FRONTIER ORBITAL MAPS

The computations and molecular modeling were performed using SPARTAN'10 software (Wavefunction, Inc., Irvine, CA, USA). The molecular structure of the $\beta$-ketoesters series (113) were designed and submitted to the calculations simulating the vacuum, in a non-ionized state and without any geometric constraint. Conformational analysis for the selection of the lowest energy conformer was performed by the molecular 
mechanics method using force field MMFF (Merck Molecular Force Field) (Halgren 1996). Thereafter the conformers were subjected to geometry optimization using the semi-empirical method RM1 (Recife Model 1) (Rocha et al. 2006). The conformer with the lowest energy was subjected to single point calculation by the DFT-B3LYP method based on quantum mechanics, with $6-31 \mathrm{G}^{*}$ basis set (Becke 1993, Lee et al. 1988, Kohn et al. 1996). Subsequently, in order to assist the understanding of the stereoelectronics aspects involved in the asymmetric reduction of the $\beta$-ketoesters (1-13) by $K$. marxianus and the favorable points for the chemical reaction, the molecular frontier orbital LUMO (Lowest Unoccupied Molecular Orbital) were evaluated (Oliveira et al. 2013).

HQSAR MODELS

The hologram QSAR method that employs fragment fingerprints as predictive variables of the activity (Rodrigues et al. 2002) were used to investigate the influence of molecular structure of $\beta$-ketoesters (113) on the conversion and enantiomeric excess of $\beta$-hydroxyester produced by $K$. marxianus activity. The asymmetric reduction of all compounds was expressed as percentage of $(S)$ - and $(R)$ enantiomers, which were converted to logarithmic values before HQSAR models preparation.

The initial set of 1-13 compounds was divided into training and test sets. The training set (11 compounds) represents structurally different compounds with diverse results obtained for the yeast activity. In order to evaluate the predictive capacity of the model the 2 remaining compounds were assigned to the test set. To avoid possible problems during the external validation, the test set containing compounds with low and high asymmetric reduction.

The HQSAR studies were performed using the SYBYL-X 1.2 software package (Tripos International, St. Louis, MO, USA). The structures of $\beta$-ketoesters were converted into fragments initially using the default fragment size of 4-7 atoms per fragment. All fragments were allocated in defined molecular hologram lengths $(53,59,61$, 71, 83, 97, 151, 199, 257, 307, 353 and 401 bins) and fragment distinction analysis was performed in terms of atoms, bonds, connectivity, hydrogen atoms and hydrogen bond donor/acceptor atoms. Since these parameters may affect HQSAR models, different combinations of these parameters were considered during the HQSAR runs (Magalhães et al. 2013). Selection of HQSAR models was done on the basis of $q^{2}$ values, known as leave-oneout cross-validated $r^{2}$, the most common statistic criteria used for model evaluation. Although the prerequisite for a predictive QSAR model is $q^{2}$ $>0.5$, is fundamental an external test validation (Golbraikh and Tropsha 2002).

Several QSAR models were generated for each distinguishing fragment based on partial least squares (PLS) analysis. All QSAR models were obtained using PLS. Moreover, internal validation was performed by leave-one-out cross-validation and the external validation was performed with the test set compounds, which were not considered for the HQSAR model development (Shinde et al. 2012).

\section{RESULTS AND DISCUSSION}

BIOCONVERSION OF $\beta$-KETOESTERS (1-6)

The yeast Kluyveromyces marxianus was able to reduce $\beta$-ketoesters (1-4) to (-)-(R)-hydroxyesters $(\mathbf{1}$ 'b-4'b) and (5 and 6) to (-)-(S)-hydroxyesters (5'a and 6'a) with different conversions and enantiomeric excess (Table I). Among them, four compounds (2'b-4'b and 6'a) exhibited enantiopurity (>99\% $e e)$ and the $(R)$-products (1'b-4'b) were obtained with high conversion levels (higher than 70\%). The IR spectra shown characteristic absorption bands of hydroxyesters compounds, such as in the stretching regions of $\mathrm{O}-\mathrm{H}$ and $\mathrm{C}=\mathrm{O}$ bonds. 
The correspondent $(R)$-enantiomers $\mathbf{1}^{\mathbf{\prime}} \mathbf{b}-\mathbf{4}^{\prime} \mathbf{b}$ were observed in gas chromatograph at 4.0, 11.2, 12.8, 16.5 minutes respectively, and the correspondent (S)-hydroxyesters 5'a and 6'a were observed at 10.9 and 23.7 minutes respectively (Figure 1).

It is noteworthy that among the synthetic method to obtain the hydroxyesters presented here, there are just few reports that use the Kluyveromyces genus (Ramos et al. 2011, Xu et al. 2013), one of which used carbonyl reductase of $K$. thermotolerans (Xu et al. 2013). The asymmetric bioreduction by whole cells of $K$. marxianus method was particularly effective in obtaining the $(R)$-hydroxyesters in high conversions and ee rate (Table I). Other methods described in the literature leading to the $(R)$-hydroxyesters $(\mathbf{1} \mathfrak{b}$, 3'b, 4'b) requires more laborious and expensive approach, that is the complete inhibition of enzymatic activity for $(S)$-enantiomer using different microorganisms and growth conditions, recombinant microorganisms or enzyme inhibitors generally toxic and volatile (Ramos et al. 2011, Venkataraman and Chadha 2015, Fow et al. 2008, Dahl and Madsen 1998, Dao et al. 1998, Srivastava et al. 2015, Chen et al. 2015, Zhang et al. 2015).

The results demonstrated that yeast $K$. marxianus(Oliveira etal.2013, Molinari etal. 1999), also easy to handle and growth like Saccharomyces cerevisiae, led to the $(R)$-hydroxyesters (1'b-4'b) without any other additive and in a greater extent than that reported for $S$. cerevisiae (Zeror et al. 2010, Mahmoodi et al. 2006). This is probably due to the different selectivity of the enzymes with specificity for the $(R)$-configuration in each yeast. On the other side, $\beta$-ketoesters 5 and $\mathbf{6}$ were reduced to their $(S)$-hydroxyesters (5'a and 6'a) with $44 \%$ and $>99 \%$ ee, respectively (Table I). If on the one hand 5'a has also been reported by different bioreduction methods (Fow et al. 2008, Bisogno et al. 2009, Nakamura et al. 1985, 1989, Patel et al. 1992), on the other there are few and recent reports about 6'a from biocatalysis of $\mathbf{6}$ acetate (Borowiecki and Bretner 2013, Liu and Liu 2015). Because of the higher ee and the simplicity of the synthetic methodology these results showed that the bioreduction method using whole cell of $K$. marxianus is an attractive alternative to obtain the enantiopure hydroxyesters (2'b- 4'b and 6'a).

\section{MAPPING OF MOLECULAR STEREOELECTRONICS} CHARACTERISTICS

In order to evaluate on the influence of chemical structures of substrates in the bioreduction using whole cell of $K$. marxianus 13 different $\beta$-ketoesters compounds (1-13) were analyzed, among which the ones presented in this paper (6 compounds) and the other seven from previously published work (Oliveira et al. 2013, Ramos et al. 2013, 2009a, b, Ribeiro et al. 2009, 2014).

Analysis of the LUMO electron density map contribution from 1-13 showed a highlighted LUMO area (blue) at keto group region that stand out its higher tendency to react with nucleophiles leading to $\beta$-hydroxyesters (Figure S1 - Supplementary Material). Moreover, based on their minimal local energy conformation, the compounds display different probabilities of nucleophilic attack on both sides of keto group, with exception of compounds $\mathbf{5}$ and $\mathbf{1 0}$ in which both sides of the keto group have been similarly exposed. However, these conformations tend to modify within the enzyme catalytic site according to the local topology, exposing preferably one side of the keto group to the amino acid residues.

Whether there is a single type of enzyme for these substrates (1-13), it would be able to make $\beta$-ketoesters conversions to both $(S)$ - and $(R)$ enantiomers. In this case, the conformational flexibility of the $\beta$-ketoester scaffold may acquire different molecular arrangements in the catalytic site of enzyme, where the functional groups of this moiety may interact with different amino acids depending on the molecular structure of the derivative. Assuming that, the $\beta$-ketoesters 
TABLE I

Bioconversion of $\beta$-ketoesters series (1-13) by Kluyveromyces marxianus to correspondent $(S)$-(1'a-13'a) or (R)-hydroxyesters (1'b-13'b).<smiles>[R2]OC(=O)C[C@@H]([R])O[R2](=O)CC</smiles>

$(1-13)$ (1'a-13'a)<smiles>[R2]OC(=O)C[C@@H]([R])O</smiles>

(1'b-13'b)

\begin{tabular}{|c|c|c|c|c|c|c|c|c|c|}
\hline \multirow{2}{*}{ Compound } & \multirow{2}{*}{$\mathbf{R}_{1}$} & \multirow{2}{*}{$\mathbf{R}_{2}$} & \multirow{2}{*}{$\begin{array}{c}R_{1} \text { volume } \\
\left(\AA^{3}\right)\end{array}$} & \multirow{2}{*}{$\begin{array}{c}\mathbf{R}_{2} \text { volume } \\
\left(\AA^{3}\right)\end{array}$} & \multirow{2}{*}{$\mathrm{C}(\%)$} & \multirow{2}{*}{$\begin{array}{c}\text { ee } \\
(\%)\end{array}$} & \multirow{2}{*}{$\begin{array}{c}\text { S(\%) } \\
\text { 1'a-13'a }\end{array}$} & \multirow{2}{*}{$\begin{array}{c}R(\%) \\
\text { 1'b-13'b } \\
\end{array}$} & \multirow{2}{*}{$\begin{array}{c}\text { Enantiomer } \\
\text { prevalent }\end{array}$} \\
\hline & & & & & & & & & \\
\hline 1 & $\sim \mathrm{CH}_{3}$ & $\sim \mathrm{CH}_{2} \mathrm{CH}_{3}$ & 33.26 & 51.85 & 99.2 & 81.1 & 9.45 & 90.55 & $R$ \\
\hline 2 & $\sim \mathrm{CH}_{2} \mathrm{CH}_{3}$ & $\sim \mathrm{CH}_{3}$ & 51.84 & 33.29 & 73.51 & 99.9 & 0.05 & 99.95 & $R$ \\
\hline 3 & $\sim \mathrm{CH}_{2} \mathrm{CH}_{3}$ & $\sim \mathrm{CH}_{2} \mathrm{CH}_{3}$ & 51.84 & 51.88 & 85.54 & 99 & 0.5 & 99.5 & $R$ \\
\hline 4 & $\sim \mathrm{C}_{3} \mathrm{H}_{7}$ & $\sim \mathrm{CH}_{2} \mathrm{CH}_{3}$ & 70.20 & 51.88 & 96.06 & 99 & 0.5 & 99,5 & $R$ \\
\hline 5 & $\sim \mathrm{CH}_{2} \mathrm{Cl}$ & $\sim \mathrm{CH}_{3}$ & 47.72 & 33.26 & 13.25 & 43.7 & 71.85 & 28.15 & $S$ \\
\hline 6 & $p-\mathrm{Cl}-\mathrm{Ph} \sim$ & $\sim \mathrm{CH}_{3}$ & 112.47 & 33.26 & 28 & 99.9 & 99.95 & 0.05 & $S$ \\
\hline 7 & $\sim \mathrm{CCl}_{3}$ & $\sim \mathrm{CH}_{2} \mathrm{CH}_{3}$ & 74.63 & 51.88 & 3.6 & 73 & 86.5 & 13.5 & $S^{a}$ \\
\hline 8 & $\sim \mathrm{CF}_{3}$ & $\sim \mathrm{CH}_{2} \mathrm{CH}_{3}$ & 47.12 & 51.88 & 81 & 29 & 64.5 & 35.5 & $S^{a}$ \\
\hline 9 & $\sim \mathrm{CH}_{3}$ & $\sim \mathrm{CH}_{3}$ & 33.26 & 33.29 & 84 & 5 & 52.5 & 47.5 & $S^{b}$ \\
\hline 10 & $\sim \mathrm{CH}_{2} \mathrm{Cl}$ & $\sim \mathrm{CH}_{2} \mathrm{CH}_{3}$ & 47.72 & 51.88 & 9.70 & 80.8 & 90.4 & 9.6 & $S^{\mathrm{c}}$ \\
\hline 11 & phenyl & $\sim \mathrm{CH}_{2} \mathrm{CH}_{3}$ & 99.10 & 51.88 & 59 & 99.9 & 99.95 & 0.05 & $S^{\mathrm{d}}$ \\
\hline 12 & $\sim \mathrm{CH}_{3}$ & tert-butyl & 33.26 & 88.20 & 64.2 & 51.5 & 75.75 & 24.25 & $S^{\mathrm{e}}$ \\
\hline 13 & $\sim \mathrm{CH}_{3}$ & benzyl & 33.26 & 99.10 & 80 & 68 & 84 & 16 & $S^{\mathrm{f}}$ \\
\hline
\end{tabular}

Literature data: ' 7' and 8' (Oliveira et al. 2013), ' 9 ' (Ramos et al. 2009b), '10' (Ribeiro et al. 2009), 'd1' (Ramos et al. 2009a), ${ }^{\mathrm{e}} 12^{\prime}$ (Ramos et al. 2013), ${ }^{\mathrm{f}} 13$ ' (Ribeiro et al. 2014).

derivatives should adjust the molecular conformation to the topology of catalytic site in complementarity with the enzymatic conformational motions.

However, in the hypothesis of the existence of two or more highly selective enzymes capable of catalyzing the asymmetric bioreduction of these $\beta$-ketoesters derivatives it would consider that the molecular structure of their substrates influence for the $(S)$-enantiomer or $(R)$-enantiomer conversion. In this case, the $\beta$-ketoesters derivatives should adjust the molecular conformation to the topology of catalytic site in complementarity with the enzymatic conformational motions.
We assume that the structure of the substituents linked to the $\beta$-ketoester scaffold is directly responsible for the steric effects by the influence on the conformation and have influence on the electropositive area at carbon atom of the keto group. The LUMO maps reinforce that bioconversion values are related to the effects of the substituents on the molecule conformations directly affecting the enzymatic asymmetric reduction of $\beta$-ketoesters (Oliveira et al. 2013, Dao et al. 1998).

\section{HQSAR MODELS}

HQSAR uses an extended form of fingerprint, known as molecular hologram which encodes 


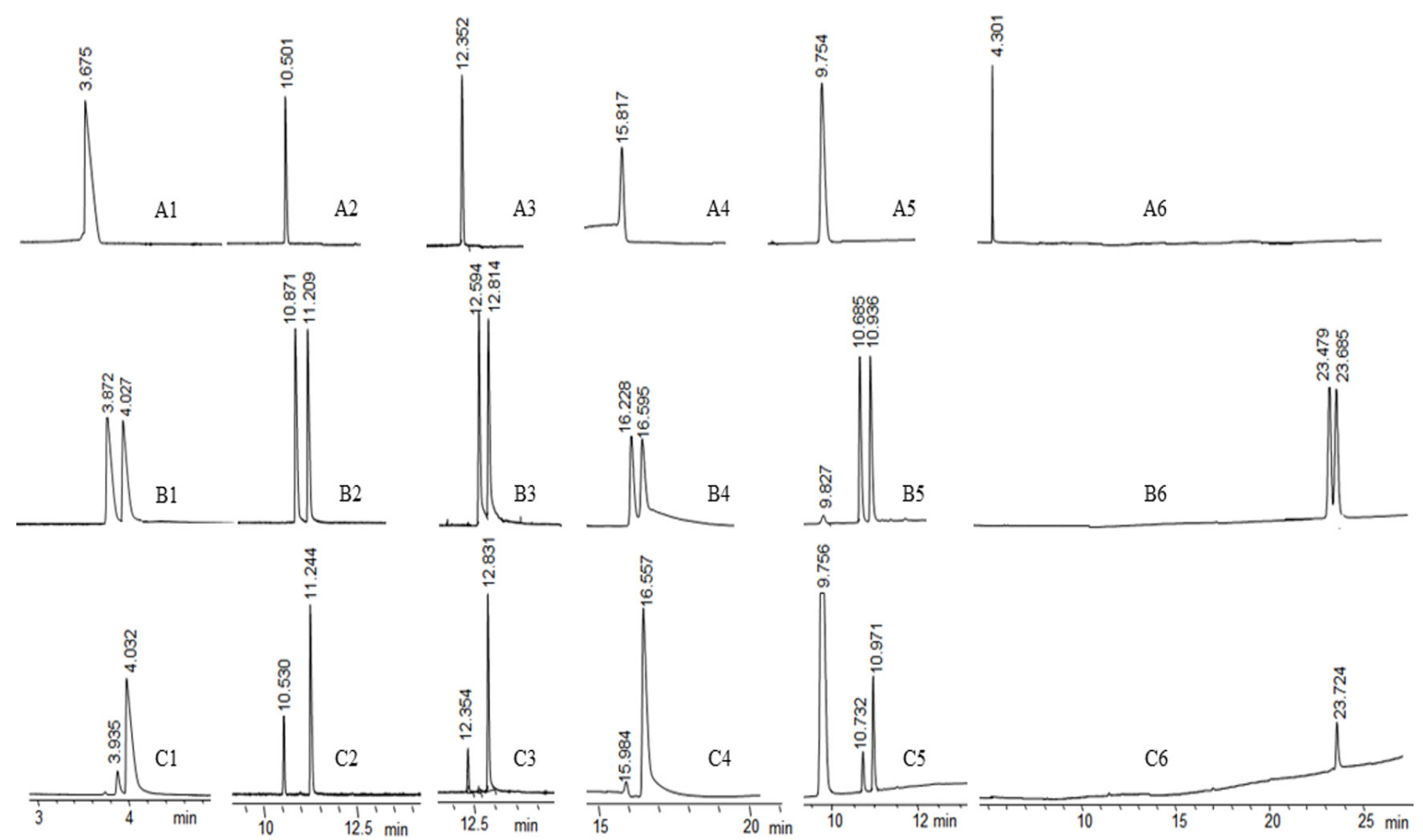

Figure 1 - Chromatograms showing the $\beta$-ketoesters and correspondent reduction products: (A1) ethyl 3-oxobutanoate; (A2) methyl 3-oxopentanoate; (A3) ethyl 3-oxopentanoate; (A4) ethyl 3-oxohexanoate; (A5) methyl 4-chloro-3-oxobutanoate, (A6) methyl 3-(4-chlorophenyl)-3-oxopropanoate; B1-B6 - racemate obtained via $\mathrm{NaBH}_{4}$ reduction; $\mathrm{C} 1-\mathrm{C} 6$ - Kluyveromyces marxianus reduction. The retention times are indicated above each chromatogram peak.

information. This requires values to be selected for the parameters that specify the hologram length, as well as the size and type of fragments to be encoded (Flower 1998). The molecular fragments were generated using the fragment distinction parameters based on atoms, bonds, connections, hydrogen atoms and hydrogen bond donor/acceptor atoms. The HQSAR models were first generated using the default fragment size (4-7 atoms) combined with various fragment types and various hologram lengths. To identify how the fragment size could influence the statistical parameters, different fragment sizes were tested $(2-5,3-6,4-7$, $5-8,6-9,7-10,8-11$, and 9-12) on the three best fragment distinction parameters of these models having the highest statistical indexes for $(S)$ - and $(R)$ - $\beta$-hydroxyester conversion. Table II shows the highlight HQSAR models.
The best HQSAR model for conversion of these $\beta$-ketoesters derivatives to $(S)$ - $\beta$-hydroxyester was

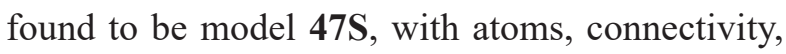
hydrogen atoms and hydrogen bond donor/acceptor atoms as the fragment distinction parameters, and 5-8 atoms as the fragment size, showing good predictive capacity $\left(q^{2}=0.75\right)$, high data fitting $\left(r^{2}=\right.$ $0.97)$, and low cross-validated standard error $\left(\mathrm{SE}_{\mathrm{cv}}\right.$ $=0.66$ ) (Table II). The descriptors contributions to bioconversion by $K$. marxianus in the model $47 \mathrm{~S}$ show the most critical parameters. The fragments of 5-8 atoms may be determinant for $(S)$-enantiomer conversion.

Regarding the best HQSAR model for bioconversion to $(R)$ - $\beta$-hydroxyester, $42 \mathbf{R}$ was the best model. With connectivity and hydrogen atoms as the fragment distinction parameter, and 8-11 atoms as the fragment size, it shows good 
predictive capacity $\left(q^{2}=0.86\right)$, high data fitting $\left(r^{2}=\right.$ $0.97)$, and low cross-validated standard error $\left(\mathrm{SE}_{\mathrm{cv}}\right.$ $=0.48$ ) (Table II). The descriptors contributions to bioconversion by $K$. marxianus in the model $\mathbf{4 2 R}$ show that the critical parameters from $\beta$-ketoesters to $(R)$-enantiomer conversion are not the same to $(S)$-enantiomer conversion.

\section{HQSAR CONTRIBUTION MAPS}

The HQSAR contribution map from these models can provide valuable insights about relationship between molecular fragments and bioconversion values in K. marxianus. Hologram QSAR uses

\section{TABLE II}

Best models summary of HQSAR statistical indexes of $\beta$-ketoesters derivatives asymmetric bioreduction for the influence of various fragment size (FS), using atoms, bonds, connectivity, hydrogen atom and hydrogen bond donor/acceptor groups as the fragment distinction (FD) parameter.

\begin{tabular}{cccccccc}
\hline \multirow{2}{*}{ Model } & \multirow{2}{*}{ FD } & \multirow{2}{*}{ FS } & \multicolumn{5}{c}{ Statistical Indexes } \\
& & & $\boldsymbol{q}^{2}$ & $\boldsymbol{r}^{2}$ & SE $_{\mathrm{cv}}$ & PC & HL \\
\hline $16 \mathrm{~S}$ & $\mathrm{~A} / \mathrm{B} / \mathrm{H}$ & $4-7$ & 0.65 & 0.92 & 0.77 & 3 & 199 \\
$23 \mathrm{~S}$ & $\mathrm{~A} / \mathrm{B} /$ & $4-7$ & 0.65 & 0.92 & 0.78 & 3 & 401 \\
& $\mathrm{C} / \mathrm{H}$ & & & & & & \\
$26 \mathrm{~S}$ & $\mathrm{~A} / \mathrm{C} / \mathrm{H} /$ & $4-7$ & 0.66 & 0.96 & 0.83 & 4 & 353 \\
& $\mathrm{DA}$ & & & & & & \\
$45 \mathrm{~S}$ & $\mathrm{~A} / \mathrm{C} / \mathrm{H} /$ & $3-6$ & 0.68 & 0.91 & 0.74 & 3 & 53 \\
& $\mathrm{DA}$ & & & & & & \\
$46 \mathrm{~S}$ & $\mathrm{~A} / \mathrm{C} / \mathrm{H} /$ & $4-7$ & 0.66 & 0.96 & 0.83 & 4 & 353 \\
& $\mathrm{DA}$ & & & & & & \\
$47 \mathrm{~S}$ & $\mathrm{~A} / \mathrm{C} / \mathrm{H} /$ & $5-8$ & 0.75 & 0.97 & 0.66 & 3 & 97 \\
& $\mathrm{DA}$ & & & & & & \\
$3 \mathrm{R}$ & $\mathrm{C}$ & $4-7$ & 0.84 & 0.96 & 0.52 & 5 & 59 \\
$13 \mathrm{R}$ & $\mathrm{C} / \mathrm{H}$ & $4-7$ & 0.84 & 0.96 & 0.52 & 5 & 59 \\
$31 \mathrm{R}$ & $\mathrm{C}$ & $5-8$ & 0.85 & 0.96 & 0.50 & 5 & 59 \\
$34 \mathrm{R}$ & $\mathrm{C}$ & $8-11$ & 0.86 & 0.97 & 0.48 & 5 & 71 \\
$39 \mathrm{R}$ & $\mathrm{C} / \mathrm{H}$ & $5-8$ & 0.85 & 0.96 & 0.50 & 5 & 59 \\
$42 \mathrm{R}$ & $\mathrm{C} / \mathrm{H}$ & $8-11$ & 0.86 & 0.97 & 0.48 & 5 & 71 \\
\hline
\end{tabular}

Abbreviations: A, atoms; B, bonds; C, connectivity; DA, hydrogen bond donor/acceptor atoms; H, hydrogen atoms; HL, hologram length; PC, principal components; $q^{2}$, leave-one-out cross-validated correlation coefficient; $r^{2}$, non-cross-validated correlation coefficient; $\mathrm{SE}_{\mathrm{cv}}$, cross-validated standard error; HQSAR, hologram quantitative structure-activity relationship. molecular holograms and PLS to generate fragment-based structure-activity relationships. According to HQSAR method, it is possible to predict the activity value of a molecule by mapping its structural fragments (Rodrigues et al. 2002). In this sense, HQSAR contribution map analysis may be used as a step on the understanding the individual atomic contributions to the prevalence of $(R)$ - or $(S)$-enantiomer bioconversion through a color code from red to green in a spectrum. The colors at the green end (yellow, green blue and green) indicate favorable contributions, whereas colors at the red end (orange, red orange and red) indicate unfavorable contributions. The neutral contributions are colored white (Figure 2).

According to the contribution map, the molecular fragment corresponding to the substituents linked to $\beta$-ketoester scaffold display important role to $(S)$ - and $(R)$-conversion. Furthermore the HQSAR contribution maps suggest that $\beta$-ketoesters scaffold is important to asymmetric reduction too. It suggests a possible influence from carbonyl of the ester group on the stabilizing the conformation in the enzyme catalytic site for $(S)$ - and $(R)$-enantiomers bioconversion. This can be seen especially in compounds $\mathbf{2 , 3}$ and $\mathbf{6}$ which have had their conversions to hydroxyesters influenced by the effect of the alkoxy groups on ester carbonyl in both models.

The $\beta$-ketoesters scaffold is the common molecular structure among the present compounds series, indicating the importance of the conformation and the position of the atoms to bioconversion. The substituents attached to $\beta$-ketoesters scaffold clearly have effects on the asymmetric reduction. According to both models, hydrogen atoms of the substituents attached to $\beta$-ketoesters scaffold should be replaced by others groups with the aim of modifying the asymmetric reduction. A rational attempt would be to modify these hydrogen atoms by bioisosteres monovalent groups such as fluorine, hydroxyl, amino and methyl groups or replace the 
(a)

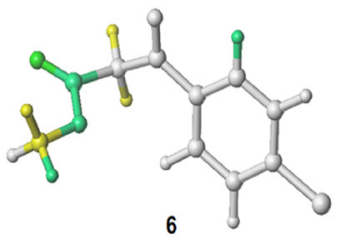

Bioreduction to
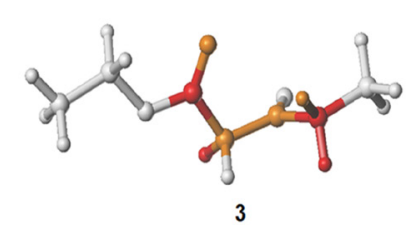

(b)
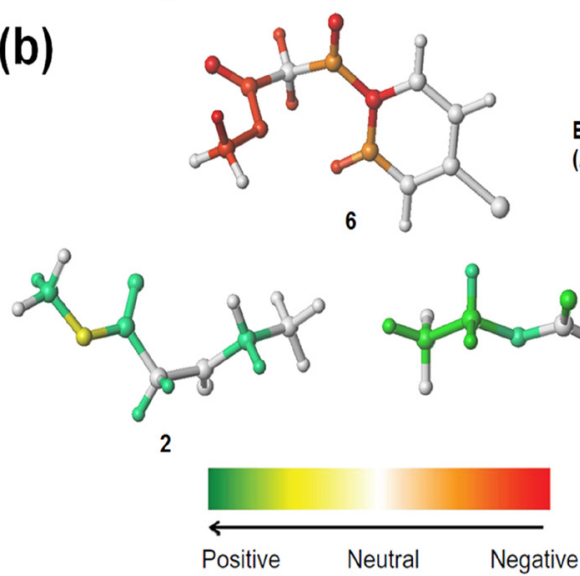

Figure 2 - Hologram quantitative structure-activity relationship (HQSAR) contribution maps of the most and least bioconverted to $(S)$-enantiomer (a) and $(R)$-enantiomer (b) by K. marxianus.

methylene bridge by divalent bioisosteres (Patani and LaVoie 1996).

\section{EXTERNAL VALIDATION OF THE BEST HQSAR} MODELS

An external validation was carried in order to access its ability to predict the bioconversion values in $K$. marxianus for the test set compounds. The experimental, predicted, and residual values (log scale converted from percentage data) for both training and test set compounds obtained for the best HQSAR models are reported in Table III. There is no presence of outliers in both models, showing the high predictive capacity. The good agreement between experimental and predicted values for the test set compounds establishes the reliability of the constructed HQSAR models: model 47S $\left(r^{2}=\right.$
$0.9743)$ and model $42 \mathbf{R}\left(r^{2}=0.9600\right)$. The residual values of the bioconversion predicted are very low and the model $42 \mathrm{R}$ predicted exactly the same values to compound $\mathbf{6 , 9 , 1 2}$ and $\mathbf{1 3}$. The predictive capacity of the HQSAR models was investigated by calculating the predictive $r^{2}$ values from the test compounds (4 and 11) which were also predicted with low residual values (Table III).

Both successful models provide important information about which molecular fragments are directly related to the bioconversion profile in K. marxianus. Moreover, these models may be used to predict the bioconversion of the untested compounds. These data would be useful for application of $K$. marxianus in bioconversion of any other $\beta$-ketoester derivatives.

\section{CONCLUSIONS}

In the present study, the wild strain Kluyveromyces marxianus was able to reduce $\beta$-ketoesters (1-6) to the corresponding chiral $\beta$-hydroxyesters. Four of these were obtained with enantiomeric purity (>99\%). Molecular investigation emphasized that the conversion rate and stereoselectivity of the enzymes over the $\beta$-ketoesters are related to their different electropositive region observed on LUMO electron density map. Moreover, the $\beta$-ketoesters series LUMO maps emphasize the importance of substituent effect and reinforce the influence of the $\beta$-ketoesters molecule conformations on enzymatic asymmetric reductions.

Also, the HQSAR contribution maps suggest a possible influence of the ester group carbonyl on the molecular conformation fit in the enzyme catalytic site for $(S)$ - and $(R)$-enantiomers bioconversion. Thus, it can be suggested that both $\beta$-ketoesters scaffold and the substituents therein influence the asymmetric reduction result. Two HQSAR models were established, one for $\beta$-ketoesters derivatives conversion to $(R)$-hydroxyesters and the other to $(S)$-hydroxyesters, which provide information 
TABLE III

Experimental and predicted $\log$ percentage values of $(S)$ - and $(R)$-enantiomers formed.

\begin{tabular}{ccccccc}
\hline \multirow{2}{*}{ Compound } & \multirow{2}{*}{ Experimental $^{\mathbf{b}}$} & \multicolumn{2}{c}{ HQSAR $^{\mathbf{b}}$} & \multicolumn{2}{c}{ HQSperimental $^{\mathbf{c}}$} & \multicolumn{2}{c}{ HQSAR $^{\mathbf{c}}$} \\
& & Predicted $^{\text {Predicted }}$ & Residual \\
\hline 1 & 0.98 & 1.13 & -0.15 & 1.96 & 1.67 & 0.29 \\
2 & -1.30 & -0.95 & 0.35 & 2.00 & 2.01 & 0.01 \\
3 & -0.30 & -0.69 & -0.39 & 1.99 & 2.12 & -0.13 \\
$4^{\mathrm{a}}$ & -0.30 & -0.23 & 0.07 & 1.99 & 2.08 & -0.09 \\
5 & 1.86 & 1.73 & 0.13 & 1.44 & 1.38 & -0.06 \\
6 & 2.00 & 2.10 & -0.10 & -1.30 & -1.30 & 0 \\
7 & 1.94 & 2.03 & -0.09 & 1.13 & 1.32 & -0.19 \\
8 & 1.81 & 1.75 & 0.06 & 1.55 & 1.32 & 0.23 \\
9 & 1.72 & 1.64 & 0.08 & 1.68 & 1.68 & 0 \\
10 & 1.96 & 2.00 & -0.04 & 0.98 & 1.18 & -0.20 \\
$11^{\mathrm{a}}$ & 2.00 & 2.17 & -0.17 & -1.30 & -0.56 & 0.74 \\
12 & 1.88 & 1.90 & -0.02 & 1.38 & 1.38 & 0 \\
13 & 1.92 & 1.79 & 0.13 & 1.20 & 1.20 & 0 \\
\hline
\end{tabular}

Notes: ${ }^{\text {a}}$ Test set compounds; ${ }^{\mathrm{b}}$ Model 47S; ${ }^{\mathrm{c}}$ Model 42R.

about the relationship between molecular fragments and K. marxianus bioconversion profile. These models may be used to predict the bioconversion of untested compounds.

\section{ACKNOWLEDGMENTS}

This research was supported by grants and fellowships from the Fundação Carlos Chagas Filho de Amparo à Pesquisa do Estado do Rio de Janeiro (FAPERJ) and Universidade Federal Fluminense (UFF).

\section{REFERENCES}

BECKE AD. 1993. A new mixing of hartree-fock and local density-functional theories. J Chem Phys 98: 1372-1377.

BISOGNO FR, LAVANDERA I, KROUTIL W AND GOTOR V. 2009. Tandem Concurrent Processes: One-Pot SingleCatalyst Biohydrogen Transfer for the Simultaneous Preparation of Enantiopure Secondary Alcohols. J Org Chem 74: 1730-1732.

BOROWIECKI P AND BRETNER M. 2013. Studies on the chemoenzymatic synthesis of (R)- and (S)-methyl 3-aryl-3-hydroxypropionates: the influence of toluenepretreatment of lipase preparations on enantioselective transesterifications. Tetrahedron: Asymmetry 24: 925-936.
CHANG JJ ET AL. 2014. A thermo- and toxin-tolerant kefir yeast for biorefinery and biofuel production. Appl Energ 132: 465-474.

CHEN X, LIU ZQ, HUANG JF, LIN CP AND ZHENG YG. 2015. Asymmetric synthesis of optically active methyl-2benzamido-methyl-3-hydroxy-butyrate by robust shortchain alcohol dehydrogenases from Burkholderia gladioli. Chem Commun 51: 12328-12331.

DAHL AC AND MADSEN JO. 1998. Baker's yeast: production of D- and L-3-hydroxy esters. Tetrahedron: Asymmetry 9: 4395-4417.

DAO DH, OKAMURA M, AKASAKA T, KAWAI Y, HIDA K AND OHNO A. 1998. Stereochemical control in microbial reduction. Part 31: Reduction of alkyl 2-oxo4-arylbutyrates by baker's yeast under selected reaction conditions. Tetrahedron: Asymmetry 9: 2725-2737.

FLORIS TP, KLUSON L, BARTEK AND PELANTOVA H. 2009. Quaternary ammonium salts ionic liquids for immobilization of chiral Ru-BINAP complexes in asymmetric hydrogenation of beta-ketoesters. Appl Catal 366: 160-165.

FLOWER DR. 1998. On the properties of bit string-based measures of chemical similarity. J Chem Inf Comp Sci 38: 379-386.

FOUKIS A, STERGIOU PY, THEODOROU LG, PAPAGIANNI M AND PAPAMICHAEL EM. 2012. Purification, kinetic characterization and properties of a novel thermo-tolerant extracellular protease from 
Kluyveromyces marxianus IFO 0288 with potential biotechnological interest. Bioresour Technol 123: 214-220.

FOW KL, POON LCH, SIM ST, CHUAH GK AND JAENICKE S. 2008. Enhanced asymmetric reduction of ethyl 3-oxobutyrate by baker's yeast via substrate feeding and enzyme inhibition. Eng Life Sci 8: 372-380.

GALINDO-LEVA LA ET AL. 2016. Growth, ethanol production, and inulinase activity on various inulin substrates by mutant Kluyveromyces marxianus strains NRRL Y-50798 and NRRL Y-50799. J Ind Microbiol Biotechnol 43: 927-939.

GHOSH AK, SHURRUSH KA AND DAWSON ZL. 2013. Enantioselective total synthesis of macrolide (+)-neopeltolide. Org Biomol Chem 11: 7768-7777.

GOLBRAIKH A AND TROPSHA A. 2002. Beware of q(2)! J Mol Graph Model 20: 269-276.

HAGEMANN B, JUNGE K, ENTHALER S, MICHALIK M, RIERMEIER T, MONSEES A AND BELLER M. 2005. A general method for the enantioselective hydrogenation of beta-keto esters using monodentate binaphthophosphepine ligands. Adv Synth Catal 347: 1978-1986.

HALGREN TA. 1996. Merck molecular force field .1. Basis, form, scope, parameterization, and performance of MMFF94. J Comput Chem 17: 490-519.

ILLANES A, CAUERHFF A, WILSON L AND CASTRO GR. 2012. Recent trends in biocatalysis engineering. Bioresour Technol 115: 48-57.

KOHN W, BECKE AD AND PARR RG. 1996. Density functional theory of electronic structure. J Phys Chem 100: 12974-12980.

LANE MM, BURKE N, KARREMAN R, WOLFE KH, O'BYRNE CP AND MORRISSEY JP. 2011. Physiological and metabolic diversity in the yeast Kluyveromyces marxianus. Anton Leeuw Int J G 100: 507-519.

LEE CT, YANG WT AND PARR RG. 1988. Development of the colle-salvetti correlation-energy formula into a functional of the electron-density. Phys Rev B 37: 785789.

LIU J AND LIU W. 2015. Producing methyl (3S)-3-(4chlorophenyl)-3-hydroxypropanoate involves adding phosphate buffer and substrate 4-methyl-benzoyl chloride. Univ Qingdao Sci \& Technology (Uyqs-C).

MAGALHÃES UDO, DE SOUZA AMT, ALBUQUERQUE MG, DE BRITO MA, BELLO ML, CABRAL LM AND RODRIGUES CR. 2013. Hologram quantitative structure-activity relationship and comparative molecular field analysis studies within a series of tricyclic phthalimide hiV-1 integrase inhibitors. Drug Des Dev Ther 7: 953-961.

MAHMOODI NO, TAJIK H, TABATABAEIAN K AND SHAHBAZI M. 2006. The enantioselective beta-keto ester reductions by Saccharomyces cerevisiae. J Serb Chem Soc 71: 889-894.
MILNER SE AND MAGUIRE AR. 2012. Recent trends in whole cell and isolated enzymes in enantioselective synthesis. Arkivoc, p. 321-382.

MOLINARI F, GANDOLFI R, VILLA R AND OCCHIATO EG. 1999. Lyophilised yeasts: easy-to-handle biocatalysts for stereoselective reduction of ketones. Tetrahedron: Asymmetry 10: 3515-3520.

MORENO AD, IBARRA D, FERNANDEZ JL AND BALLESTEROS M. 2012. Different laccase detoxification strategies for ethanol production from lignocellulosic biomass by the thermotolerant yeast Kluyveromyces marxianus CECT 10875. Bioresour Technol 106: 101-109.

NAKAMURA K, HIGAKI M, USHIO K, OKA S AND OHNO

A. 1985. Stereochemical control of microbial reduction .2. Reduction of beta-keto-esters by immobilized bakersyeast. Tetrahedron Lett 26: 4213-4216.

NAKAMURA K, KAWAI Y, OKA S AND OHNO A. 1989. Stereochemical control in microbial reduction .8. Stereochemical control in microbial reduction of betaketo-esters. B Chem Soc Jpn 62: 875-879.

NAKAMURA K, YAMANAKA R, MATSUDA T AND HARADA T. 2003. Recent developments in asymmetric reduction of ketones with biocatalysts. Tetrahedron: Asymmetry 14: 2659-2681.

NG JF AND JAENICKE S. 2009. Immobilized Whole Cells as Effective Catalysts for Chiral Alcohol Production. Aust J Chem 62: 1034-1039.

OLIVEIRA SSS, DIAS LRS, BARBOSA NC, BELLO ML, NOVAES FJM, RAMOS M, AQUINO-NETO FR AND FIAUX SB. 2013. Enantioselective bioreduction of ethyl 4,4,4-trihalide-3-oxobutanoate by Kluyveromyces marxianus. Tetrahedron Lett 54: 3067-3070.

OLIVEIRA SSS, FIAUX SB, BARRETO IRL, MURI EMF, RAMOS M, AQUINO-NETO FR AND DIAS LRS. 2014. Glycerol as green solvent for efficient obtention of beta hydroxyesters. Quim Nova 37: 545-548.

PATANI GA AND LAVOIE EJ. 1996. Bioisosterism: A rational approach in drug design. Chem Rev 96: 31473176.

PATEL RN, MCNAMEE CG, BANERJEE A, HOWELL JM, ROBISON RS AND SZARKA LJ. 1992. Stereoselective reduction of beta-keto-esters by Geotrichum candidum. Enzyme Microb Tech 14: 731-738.

PILLI RA AND RIATTO VB. 1998. A chemoenzymatic synthesis of the sex pheromone of Lasioderma serricorne F. J Brazil Chem Soc 9: 571-576.

RAMOS AS, RIBEIRO JB, LOPES RO, LEITE SGF AND SOUZA ROMA. 2011. Highly enantioselective bioreduction of ethyl 3-oxohexanoate. Tetrahedron Lett 52: 6127-6129.

RAMOS AS, RIBEIRO JB, LOPES RO AND SOUZA ROMA. 2013. Whole cells in enantioselective reduction of tert-butyl acetoacetate. Synthetic Commun 43: 1611-1618. 
RAMOS AS, RIBEIRO JB, VAZQUEZ L, FIAUX SB, LEITE SGF, CRUZ RA, RAMOS MCKV, AQUINO-NETO FR AND ANTUNES OAC. 2009b. On the microbial reduction of ethyl alpha-methylacetoacetate. Tetrahedron: Asymmetry 20: 559-561.

RAMOS AS, RIBEIRO JB, VAZQUEZ L, FIAUX SB, LEITE SGF, RAMOS M, AQUINO-NETO FR AND ANTUNES OAC. 2009a. Immobilized microorganisms in the reduction of ethyl benzoylacetate. Tetrahedron Lett 50: 7362-7364.

RATOVELOMANANA-VIDAL V, GIRARD C, TOUATI R, TRANCHIER JP, HASSINE BB AND GENET JP. 2003. Enantioselective hydrogenation of beta-keto esters using chiral diphosphine-ruthenium complexes: Optimization for academic and industrial purposes and synthetic applications. Adv Synth Catal 345: 261-274.

REGIL R AND SANDOVAL G. 2013. Biocatalysis for biobased chemical. Biomolecules 3: 812-847.

RIBEIRO JB, RAMOS AS, FIAUX SB, LEITE SGF, RAMOS MCKV, AQUINO-NETO FR AND ANTUNES OAC. 2009. Immobilized microorganisms in the reduction of ethyl 4-chloro acetoacetate. Tetrahedron: Asymmetry 20: 2263-2266.

RIBEIRO JB, RAMOS AS, LOPES RD, SILVA GVV AND SOUZA R. 2014. Whole cells in enantioselective reduction of benzyl acetoacetate. Braz J Microbiol 45: 929-932.

ROCHA GB, FREIRE RO, SIMAS AM AND STEWART JJP. 2006. RM1: A reparameterization of AM1 for $\mathrm{H}, \mathrm{C}, \mathrm{N}, \mathrm{O}$, P, S, F, Cl, Br, and I. J Comput Chem 27: 1101-1111.

RODRIGUES CR, FLAHERTY TM, SPRINGER C, MCKERROW JH AND COHEN FE. 2002. CoMFA and HQSAR of acylhydrazide cruzain inhibitors. Bioorg Med Chem Lett 12: 1537-1541.

RODRIGUEZ S, SCHROEDER KT, KAYSER MM AND STEWART JD. 2000. Asymmetric synthesis of betahydroxy esters and alpha-alkyl-beta-hydroxy esters by recombinant Escherichia coli expressing enzymes from baker's yeast. J Org Chem 65: 2586-2587.

SEEBACH D, ZUGER MF, GIOVANNINI F, SONNLEITNER B AND FIECHTER A. 1984. Preparative microbial reduction of beta-oxoesters with Thermoanaerobium brockii. Angew Chem Int Edit 23: 151-152.

SHELDON RA. 2016. Biocatalysis and green chemistry. In: Patel RN (Ed), Green Biocatalysis. Hoboken, New Jersey: J Wiley \& Sons, Inc., USA, p. 1-16.

SHINDE RN, SRIKANTH K AND SOBHIA ME. 2012. Insights into the permeability of drugs and drug-like molecules from MI-QSAR and HQSAR studies. J Mol Model 18: 947-962.

SPARTAN'10 software. Wavefunction Inc., Irvine, CA, USA.

SRIVASTAVA G, PAL M, KAUR S AND JOLLY RS. 2015. A highly efficient designer cell for enantioselective reduction of ketones. Catal Sci Tech 5: 105-108.

SYBYL-X 1.2 software. Tripos International, St. Louis, MO, USA.

VENKATARAMAN S AND CHADHA A. 2015. Biocatalytic deracemisation of aliphatic beta-hydroxy esters: Improving the enantioselectivity by optimisation of reaction parameters. Ind Microbiol Biotechnol 42: 173-180.

WACHTMEISTER J AND ROTHER D. 2016. Recent advances in whole cell biocatalysis techniques bridging from investigative to industrial scale. Curr Opin Biotech 42: 169-177.

WANG XT, CHEN XH, XU Y, LOU WY, WU H AND ZONG MH. 2013. Biocatalytic anti-Prelog stereoselective reduction of ethyl acetoacetate catalyzed by whole cells of Acetobacter sp CCTCC M209061. J Biotechnol 163: 292-300.

WEI P, GAO JX, ZHENG GW, WU H, ZONG MH AND LOU WY. 2016. Engineering of a novel carbonyl reductase with coenzyme regeneration in $E$. coli for efficient biosynthesis of enantiopure chiral alcohols. J Biotechnol 230: 54-62.

XU J, XU G, YU H AND PAN J. 2013. Carbonyl reductase of Kluyveromyces thermotolerans for asymmetric reduction of prochiral carbonyl compounds to prepare chiral alcohols eds. A. E. C. U. o. S. and \& Technology. Peop. Rep. China.

ZEROR S, COLLIN J, FIAUD JC AND ZOUIOUECHE LA. 2010. Enantioselective ketoester reductions in water: a comparison between microorganism- and rutheniumcatalyzed reactions. Tetrahedron: Asymmetry 21: 12111215.

ZHANG YJ, ZHANG WX, ZHENG GW AND XU JH. 2015. Identification of an epsilon-Keto Ester Reductase for the Efficient Synthesis of an (R)-alpha-Lipoic Acid Precursor. Adv Synth Catal 357: 1697-1702.

\section{SUPPLEMENTARY MATERIAL}

Figure S1 - Lowest Unoccupied Molecular Orbital (LUMO) electron density map on both sides of the $\beta$-ketoesters (1- 13). The electron-deficient area is shown in shades of blue ranging from pale to deep blue. 